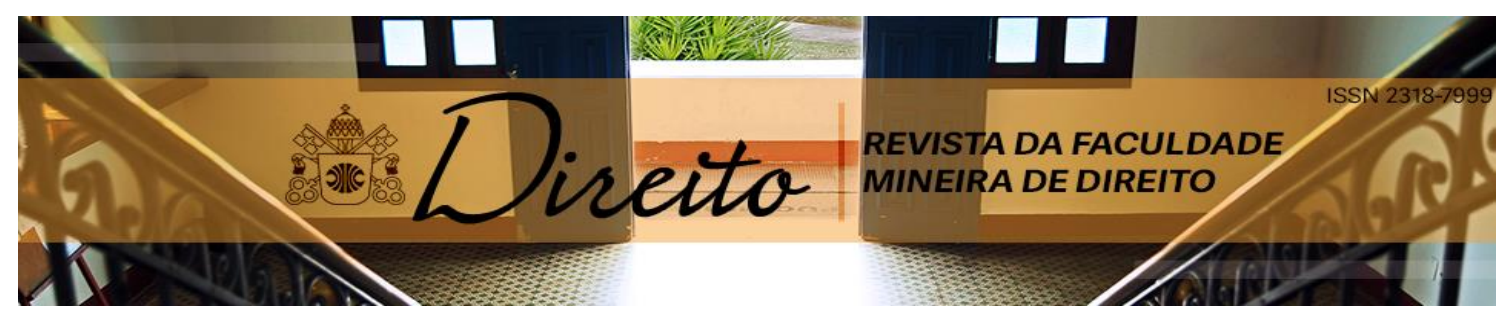

\title{
NOTAS SOBRE EL PROCESO DE CONSTRUCCIÓN JURÍDICA DE LA NEGOCIACIÓN Y EL CONVENIO COLECTIVO
}

\section{NOTES ON THE PROCESS OF LEGAL CONSTRUCTION OF NEGOTIATION AND THE COLLECTIVE AGREEMENT}

\section{Resumen}

Mario Garmendia Arigón ${ }^{1}$

En el presente artículo se realiza una presentación panorámica y sinóptica de las primeras fases del proceso histórico que llevó a que la negociación y el convenio colectivo pasaran de ser considerados conductas proscriptas y perseguidas penalmente a ser respectivamente reconocidos como un bien jurídico destinatario de tutela especial y como una norma jurídica que tiene un lugar en un complejo sistema de las fuentes del Derecho. Entre un extremo y otro de esa línea de tiempo, hay un rico contenido de búsquedas y debates a propósito del encuadramiento jurídico que correspondía a aquellas figuras, que terminaron provocando una importante transformación en la teoría general del Derecho.

Palabras-Claves: Negociación colectiva - Convenio colectivo - Naturaleza jurídica de los convenios colectivos - Fuentes del Derecho.

\begin{abstract}
This article presents a panoramic and synoptic presentation of the first phases of the historical process that led to the negotiation and collective agreement from being considered proscribed prosecuted and criminally prosecuted respectively to be recognized as a legal right recipient of special protection and As a legal norm that has a place in a complex system of sources of law. Between one end and another of that time line, there is a rich content of searches and debates about the legal framework that corresponded to those figures, which ended up provoking a major transformation in the general theory of Law.
\end{abstract}

Key-words: Collective bargaining - Collective agreement - Legal nature of collective agreements - Sources of law

Artigo Recebido em 20 de junho de 2016 e aprovado em 15 de setembro de 2016.

1 Doutor em Direito pela Universidade de la República - Uruguai. Professor da Universidad de la República, Montevideo, Uruguai. 


\section{INTRODUÇÃO}

\section{ORIGEN: LOS FACTORES DE RESISTENCIA}

El origen de lo que hoy conocemos como negociación colectiva, se encuentra directamente vinculado al proceso de la industrialización y, más concretamente, a la aparición y desarrollo de las grandes usinas industriales, que fueron el entorno en que surgió y se desenvolvió el movimiento obrero'.

Pero su reconocimiento y aceptación fue bastante retrasado en el escenario general en que la llamada cuestión social ${ }^{2}$ desplegaba sus efectos e, incluso, considerablemente más tardío que el propio inicio o lanzamiento de las, por entonces denominadas, leyes de fábricas.

Diversas fueron las razones que determinaron que el despegue del fenómeno no se produjera más anticipadamente.

Una de las más significativas seguramente debió ser la fuerte resistencia que le opusieron los empleadores, quienes no se sentían para nada cómodos ante la perspectiva de terminar siendo forzados a ceder terreno en lo atinente a la determinación de las condiciones de trabajo que habrían de imperar en el seno de la empresa, aspecto en que, por entonces, ejercían un poder de dominación ${ }^{3}$ prácticamente ilimitado ${ }^{4}$. No es difícil imaginar la repulsión que debía provocar a aquellos patrones la idea de quedar obligados a negociar con los trabajadores coaligados las condiciones que antes podían imponer de manera inconsulta y totalmente discrecional ${ }^{5}$.

A esto se sumaban las políticas represivas que desplegaban los Estados ante las manifestaciones colectivas del incipiente movimiento obrero. Esas políticas estatales, rigurosamente opuestas a aceptar los nuevos fenómenos que surgían junto con la industrialización, se proyectaba en una normativa que declaraba ilícita, tanto en el plano civil como penal, cualquier intento de coalición y actuación colectiva. "El Estado se defiende contra

1.- $\quad$ ARIGÓN, Mario Garmendia. “La empresa y sus mutaciones desde la perspectiva del Derecho del Trabajo", in rev. Derecho Laboral, № 229, enero-marzo 2008.

2.- BARBAgELATA, Héctor-Hugo, Curso sobre la Evolución del Pensamiento Juslaboralista, FCU, Mdeo., 2009, p. 16 y ss.

3.- Decía BARBAGELATA que "Al examinar las respuestas del derecho a la cuestión social hay que tener presente que, como Hugo SINZHEIMER lo puso de manifiesto en el primer tercio del siglo XX, ha existido y por mucho tiempo ha ejercido plena supremacía, un derecho no-etático de dominación, anterior y aún concomitante con la legislación laboral". BARBAGELATA, H.-H., Curso sobre la Evolución, cit., p. 75, con cita de SINZHEIMER, Hugo, "La théorie des sources du droit et le droit ouvrier", in Annuaire de l'Institut International de Philosophie du Droit et de Sociologie Juridique, 1934-1935, pp. 72-81.

4.- Según Mario DE LA CUEVA “Los empresarios, que se sabían y actuaban como soberanos de su empresa, nunca discutieron con cada trabajador las condiciones de trabajo, sino que, desde un principio, formularon lo que se llamó la doctrina del reglamento de trabajo de la fábrica". DE LA CUEVA, Mario, "El contrato colectivo en la nueva Ley Federal de Trabajo de México", in Estudios en Memoria de Francisco De Ferrari, Facultad de Derecho y Ciencias Sociales, Mdeo., 1973, p. 401.

5.- De manera muy gráfica, en un artículo publicado en 1908, SALEILLES decía que el convenio colectivo era visto como una suerte de "constitución garantida por los patronos, un poco a la manera que, al principio del S. XIX, los reyes otorgaban una Constitución a sus pueblos". "Note sur le contrat collectif du travail". Bulletin de la societé d'Etudes legislatives, 1908, NI, p. 85, cit. por GALLART FOLCH, Alejandro, Las convenciones colectivas de trabajo en la doctrina y en las legislaciones extranjeras y española, Comares, Granada, 2000, p. 14, con importante prólogo de José Luis MONEREO PÉREZ. 
el derecho no estatal', describía Sinzheimer ${ }^{6}$, determinando que las relaciones laborales nacieran en el seno del Derecho Penal'.

Estos abordajes legislativos estaban inspirados en el liberalismo que dominaba la cultura jurídica de la época, que sólo podía aceptar la intervención de la ley que estuviera dirigida a garantizar la más plena libertad de los contratantes. Precisamente, con base en ese fundamento, inmediatamente después del triunfo de la Revolución francesa, fue aprobado el denominado decret D'Allarde (2-17 de marzo de 1791), que proclamó que "toda persona será libre de hacer aquel negocio o de ejercer la profesión, arte u oficio que estime conveniente..." 8 y tres meses después (14-17 de junio de 1791), la célebre ley Le Chapelier, que durante casi un siglo sirvió como modelo para una tendencia legislativa que se proyectó en una amplia nómina de normas prohibitivas y represivas que fueron aprobadas en diversos países ${ }^{9}$. El proceso de descriminalización se produjo muy lentamente en los países europeos y, en todos los casos, cuando ya se encontraba bien avanzado el siglo $\mathrm{XIX}^{10}$.

A la hora de retrasar el reconocimiento jurídico de los nuevos fenómenos, a los anteriores factores se agregaba otro, no menos significativo: la gran incomodidad que para los juristas de la época aparejaban las extrañas manifestaciones regulatorias que acompañaban al

6.- SINZHEIMER, Hugo, "Teoría de las fuentes del Derecho y el Derecho obrero", in Annuaire de I'Institut International de Philosophie du Droit et de Sociologie juridique (1934-1935), Travaux de la première session. Le problème de sources du Droit Positif, Paris, 1934, traducido por la Dra. María Inés Capucho.

7.- BAYLOS Grau, Antonio, y TERRADILLOS, Juan, Derecho Penal del Trabajo, Trotta, Madrid, 1990, p. 15.

8.- El texto de la norma está accesible en Lois annotées, ou, Lois, décrets, ordonnances, avis du Conseil d'Etat, etc., avec notes historiques, de concordance et de jurisprudence (Google eBook), France, Recueil Sirey, 1854 [http://books.google.com.uy/books?]. El concepto fue elevado en 1793 a rango constitucional (art. 13 de la Constitución francesa: "Ningún género de trabajo, cultura, comercio, podrá ser prohibido a la industria de los ciudadanos"). También: BRUN, André y GALLAND, Henri, Droit du Travail, 2a ed., t. I, Sirey, París, 1978, p. 8; DURAND, Paul y JAUSSAUD, R., Traité de Droit du Travail, T. I, Dalloz, París, 1947, p. 62; CAMERLYNCK, G.H. y LYON-CAEN, G., Derecho del Trabajo, trad. de la 5a ed. francesa, Ed. Aguilar, Madrid, p. 8; OLSZAK, Norbert, Histoire du Droit du Travail, ed. Economica, Paris, 2011, p. 23-24, BERTOZZO, Matthieu, "Le décret d'Allarde des 2 et 17 mars 1791 ou la matérialisation des idées libérales de la Révolution française", Revue Générale du Droit, http://www.revuegeneraledudroit.eu

9.- $\quad{ }^{B}$ RUN' A. y GALLAND, H., Droit du Travail, 2a ed., t. I, Sirey, París, 1978, p. 8; DURAND' P aul y JAUSSAUD' R., Traité de

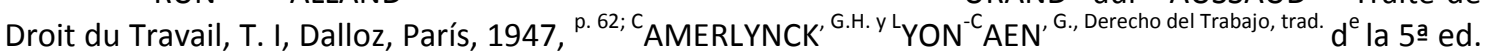

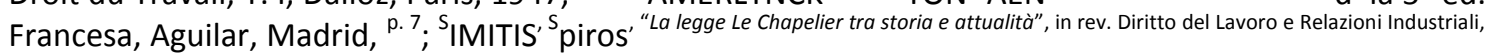
$N^{\circ} 48,1990$. En América Latina también es posible encontrar algunos ejemplos alineados en esta política normativa represiva de la actividad sindical. En Argentina puede citarse la llamada "ley de Residencia", de 22 de noviembre de 1902, que habilitaba al Poder Ejecutivo, sin intervención judicial, a ordenar la salida del territorio argentino a todo extranjero que perturbara el orden público. Asimismo, de 1910, la denominada "ley de defensa social", con un tenor severamente represivo, reglamentó el derecho de reunión (concediendo a la policía la autoridad para negarlo o restringirlo a voluntad) y otros derechos fundamentales. Al respecto: PALACIOS, Alfredo L., El Nuevo Derecho, Lajouane \& Cía., Editores, Bs. As., 1920, p. 170 y 174. Algo similar aconteció en Brasil con el decreto 1.641, del 7 de enero de 1907, norma conocida como "Ley de Adolfo Gordo", que permitía la expulsión de extranjeros que por cualquier motivo pudieran comprometer la seguridad nacional o la tranquilidad pública (vide: http://www.ebooksbrasil.org/eLibris/gordo.html).

10.- En Gran Bretaña se reconoció la libertad de asociación en 1824; en Francia recién en 1884 se derogaron las normas que penalizaban la constitución de sindicatos y la realización de huelgas (los delitos habían sido tipificados en el Código Penal de 1810, arts. 414 a 416), mientras que en Alemania, algunos Estados levantaron las prohibiciones entre 1841 y 1859, pero no fue sino hasta 1872 que una ley del recién unificado imperio generalizó las libertades. DE LA CUEVA, M., El Nuevo Derecho Mexicano del Trabajo, t. I, Porrúa, 19ạ edición, México, 2003, p. 17. 
desarrollo fabril, para las que no se encontraba fácil ubicación en ninguna de las categorías conceptuales con las que aquellos estaban acostumbrados a manejarse.

La aparición de la negociación colectiva y el producto de ella resultante, el convenio colectivo, tendrían que provocar grandes cambios en los conceptos jurídicos por entonces aceptados, haciendo que los juristas tuvieran que enfrentarse al importante desafío de buscarles alguna explicación a aquellos fenómenos con apariencia contractual, pero con pretensión de desplegar efectos erga omnes, propiedad que sólo podía reconocerse a la ley ${ }^{11}$.

Por su parte, desde el propio movimiento obrero se enfrentaba con bastante recelo la idea de dialogar y negociar con los patrones. No era poco habitual que los trabajadores estuvieran fuertemente inspirados por consignas que los alentaban a desestimar cualquier gesto que pudiera tener apariencia de transaccionalidad con el sistema capitalista. Alejandro Gallart Folch -profesor de la Universidad de Barcelona, conceptualizado por Monereo como uno de los fundadores del Derecho del trabajo contemporáneo ${ }^{12}$ - especulaba con que allí podía encontrarse la explicación de que los convenios colectivos hubieran tenido un desarrollo mucho más rápido en Gran Bretaña que en Europa Continental, donde muchos sindicatos no sentían ningún apego por la moral burguesa y el valor de la palabra dada, y aceptaban con más beneplácito la idea de Lenin de que "el engaño es lícito en la ininterrumpida lucha contra la burguesía"13.

\section{LANZAMIENTO Y ASCENSO}

Se ha dicho que el cambio de suerte que a partir de las primeras décadas del siglo XX comenzó a evidenciar la negociación colectiva como instrumento de regulación de las condiciones de trabajo, no puede ser atribuido, precisamente, a una victoria épica de las organizaciones obreras. Por supuesto, tampoco fue la consecuencia de las especulaciones académicas acerca de las ventajas o desventajas que podía traer consigo el desarrollo de la contratación colectiva ${ }^{14}$.

En realidad, otros factores parecen haber sido bastante más determinantes para que aquello aconteciera.

Al respecto, en una obra monográfica de 1922, el reconocido economista francés, Gaëtan Pirou, apreciaba que "si en nuestra época la fijación de las condiciones de trabajo se hace, cada vez más, de una manera colectiva, no es sólo porque los obreros encuentren en su agrupación un medio de corregir la inferioridad en que se hallaban cuando se presentaban aislados en el mercado de trabajo y con premuras para contratarse, es, también, que en el estado actual de la vida económica, las condiciones de trabajo y de la producción revisten, fatalmente, el aspecto de reglas uniformes. La diversidad de las situaciones individuales compatible con el pequeño oficio, no lo es con la gran industria y la única alternativa verdadera es saber si estas condiciones uniformes se establecerán por el patrono, unilateralmente y en función de sus intereses particulares, o por una colaboración del elemento patronal y del elemento obrero",15.

Sin embargo, a la imperiosa necesidad de darle uniformidad a la organización del trabajo, que venía determinada por las propias exigencias del proceso de industrialización y de la producción en masa, se vino a agregar una circunstancia que a la postre resultó fundamental: el comienzo de la primera guerra mundial y la gravitación que tuvieron una serie de hechos resultantes de la misma, en particular, el fortalecimiento del rol de los Estados en materia

11.- V. infra, Cap. III.

12.- MONEREO PÉREZ, José Luis, Teoría jurídica del convenio colectivo: su elaboración en la ciencia de Derecho. Estudio Preliminar al libro de GALLART FOLCH, Las convenciones colectivas de condiciones de trabajo en la doctrina y en las legislaciones extranjeras y española, Comares, Granada, 2000, p. XI.

13.- GALLART FOLCH, A., op. cit., p. 15.

14.- DE FERRARI, F., op. cit., p. 376.

15.- PIROU, Gaëtan, "Les problemes de contrats collectifs de travail en France”, Revue Intern. du Travail, Vol. V, 1922, p. 41, cit. por GALLART FOLCH, A., op. cit., p. 13. 
económica y social ${ }^{16}$, rol que no abandonaron luego de finalizada la contienda bélica, sino que, al contrario, profundizaron.

Entre nosotros, en una obra publicada en 1937, Gustavo Gallinal ${ }^{17}$ señalaba que "La legislación del trabajo surgió profundamente renovada del seno de las catástrofes que devastaron la economía de los grandes países industriales en el curso de este siglo. Para alimentar la insaciable hoguera de la guerra "totalitaria" de 1914-1918 los pueblos debieron disponerse a inmolar todas sus riquezas económicas, espirituales y humanas. Fue necesario apretar en haz macizo fuerzas, partidos, clases discordantes, sofocar disidencias, prevenir defecciones, satisfacer las demandas del proletariado en la hora del sangriento sacrificio, sembrar promesas para el porvenir. Nació así una legislación de guerra que ha marcado en buena parte las orientaciones del movimiento jurídico posterior" ${ }^{18}$.

En el período de entreguerras, el instrumento de la negociación colectiva ya estaba muy ampliamente difundido, especialmente en los países más industrializados.

Un claro indicio de la importancia que adquirió la negociación, puede notarse a partir de la especial atención que comenzó a prestarle la Organización Internacional del Trabajo. En la Tercera Conferencia de Estadísticas del Trabajo, convocada 1926 en el seno de aquella novel Organización Internacional, fueron sistematizados los datos que se consideraba deseable que aparecieran en las estadísticas sobre convenios colectivos ${ }^{19}$.

Además, en las Memorias del Director de la Oficina Internacional del Trabajo de los años inmediatamente posteriores (1928 y 1930), se incluyeron extensos pasajes referidos al movimiento mundial de los convenios colectivos ${ }^{20}$ y en 1930 la misma Oficina publicó las primeras estadísticas sobre convenios colectivos ${ }^{21}$, que dejaron en evidencia las importantes dimensiones que, en especial en los países industrializados, había comenzado a adquirir el fenómeno en los años veinte.

16.- OUALID Y PIEQUENARD explican la gran influencia que en relación a la negociación colectiva tuvo la guerra: 1) los Estados se convirtieron en productores y predicaron con el ejemplo de una actitud concertadora; 2) también los Estados acrecentaron enormemente su poder soberano; 3) con la guerra, los intereses individuales quedaron claramente subordinados a los intereses de la nación; 4) los Estados disponen de toda la mano de obra ("movilizados") lo que le permite ejercer gran presión sobre empleadores, demandantes de mano de obra; 5) los Estados son, además, los clientes más importantes o únicos de las empresas industriales, lo que les permite ejercer gran presión sobre ellas (Salaires et Tarifs. Conventions collectives et grèves, Colección Histoire economique et sociale de la guerre mondiale, Dotation Carnegie pour la Paix internationale), cit. por GALLART FOLCH, A., op. cit., p. 15. Adviértase que, según estadísticas que en 1922 manejaba PIROU, casi un setenta por ciento de los convenios colectivos celebrados en Francia entre 1914 y 1918, lo fueron por iniciativa o por presión estatal.

17.- Siendo legislador, Gustavo GALLINAL presentó en 1923 a la Cámara de Representantes el proyecto de ley para la creación de la cátedra de Legislación del Trabajo y de Previsión Social, en la Facultad de Derecho de la Universidad de la República. Dicho proyecto se convertiría luego en la Ley № 7.819, que fue promulgada el 7 de febrero de 1925. Años más tarde, GALLINAL se convertiría en catedrático de la materia, sucediendo a Emilio FRUGONI. V.: Derecho del Trabajo: pasado, presente y futuro, 75ㅇaiversario de la creación de la cátedra, Fac. de Derecho, Univ. de la República, Mdeo. 2000, p. 12 y ss. y p. 45 y ss.

18.- GALLINAL, Gustavo, "Últimas transformaciones de la legislación del trabajo en Francia", in Ensayos, N 15, Mdeo., setiembre de 1937, p. 12.

19.- BIT, Etudes et documents, Serie N, "Statisques”, núm. 12, cit. por GALLART FOLCH, A., op. cit., p. 19.

20.- GALLART FOLCH, A., op. cit., p. 19.

21.- Antes, en 1921 y 1929, el francés RAYNAUD había publicado otras estadísticas sobre convenios colectivos en Francia y el resto Europa. Cfe. GALLART FOLCH, A., op. cit., p. 19 y ss. 


\section{EL PROCESO DE ENCUADRAMIENTO JURÍDICO}

\section{1) La incómoda búsqueda de la "categoría adecuada"}

Durante mucho tiempo el convenio colectivo no consiguió que se le reconociera un lugar en el sistema de las fuentes del Derecho. Aceptar algo así resultaba del todo imposible en el marco de una cultura jurídica dominada por la idea de que "Derecho" era, rigurosamente, lo mismo que "Ley" y en la que, naturalmente, sólo se reconocía al Estado la potestad de crear normas jurídicas.

La búsqueda de explicaciones para el desconcertante fenómeno de los convenios colectivos acaparó la atención de los juristas durante casi todo el siglo XIX y las primeras décadas del siglo XX. Inicialmente, las especulaciones siempre giraban en torno a la noción del "contrato" y, tomándola como eje, el gran dilema a despejar se centraba en tratar de encontrar dónde y cómo estaba presente en las convenciones colectivas, el consentimiento o manifestación de la voluntad de los individuos que, sin haber participado en la negociación o en su celebración, resultaban, sin embargo, alcanzados por sus disposiciones.

En el decurso de ese proceso fueron elaboradas variadas e ingeniosas teorías, como la del contrato preparatorio o preliminar, de la serie de contratos de adhesión, de la transacción, de la asociación entre trabajadores y empleadores, del mandato, la de la estipulación para otro, del cuasi contrato de gestión de negocios, la de la personalidad moral ficticia, del contrato innominado o sui generis ${ }^{22}$ y otras ${ }^{23}$. Pero, en realidad, se trataba nada más que de un ejercicio de lo que Scelle denominara "la manía de las categorías jurídicas" ${ }^{\text {"4 }}$ y ninguna de ellas acertaba a explicar las características fundamentales de aquello que Francesco Carnelutti identificara como un extraño "ibrido, che ha il corpo del contratto e l'anima della legge" 25 .

Paulatinamente comenzaba a quedar en evidencia que no era nada adecuado tomar como punto de partida al contrato para encontrarle una explicación plausible a la naturaleza del convenio colectivo, para finalmente llegar a la conclusión que se resume en la idea sintetizada por Gallart Folch: la convención colectiva es, por su naturaleza íntima, distinta del contrato y es una ley en el sentido amplio de esta palabra ${ }^{26}$.

2) Rompiendo los moldes: el reconocimiento de la actividad jurídico-normativa del grupo profesional

A partir del último cuarto del siglo XIX se inició un profundo proceso renovador de la teoría general del Derecho, en el que participaron diversos movimientos jurídico-filosóficos que, pese a las notorias diferencias que entre sí presentaban, conjugaron una serie de lineamientos convergentes que apuntaban a generar un "clima cultural",27 que, a partir de la impugnación de

22.- LOTMAR, Phillip, "Contratti di tariffa tra datori e prestatori di lavoro", in Giornale di diritto del lavoro e di relazioni industriali (DLRI), no 22, 1984, p. 309 y ss. V. BARBAGELATA, H.-H., Curso sobre la Evolución, cit., p. 134 y MONEREO PÉREZ, J.L., cit., p. XVIII y XXIX.

23.- Para profundizar en cada una de estas teorías: GALLART FOLCH, A., Las convenciones colectivas..., cit., p. 63 y ss.; DE LA CUEVA, M., "El contrato colectivo de trabajo en...", cit., p. 463 y ss., BARBAGELATA, H.-H., Curso sobre la Evolución..., cit., p. 127 y ss.

24.- BARBAGELATA destaca esta idea de Georges SCELLE como "una de las afirmaciones más importantes que formuló", pues diferencia la forma de encarar los problemas interpretativos por el Derecho Civil y el Derecho del Trabajo. El primero parte de "descifrar las grandes líneas de una situación concreta para, a través de esa abstracción, buscarle ubicación entre las categorías ya establecidas por el Derecho Civil, incluso forzando sus contornos hasta conseguir ese objetivo". "Conforme a la concepción de SCELLE -prosigue BARBAGELATA- en el Derecho del Trabajo se debe proceder de otra manera, o sea que cada situación concreta debe ser examinada de acuerdo con los principios generales del sistema, pero sin encasillarla en una categoría preestablecida, que se presume válida para todos los casos". BARBAGELATA, H.-H., Curso sobre la Evolución..., cit., p. 129-130.

25.- CARNELUTTI, Francesco, Lezioni di diritto industriale: teoria del regolamento collettivo dei rapporti di lavoro, A. Milani, 1927, p. 108.

26.- GALLART FOLCH, A., Las convenciones colectivas..., cit., p. 133.

27.- MONEREO PÉREZ, J.L., Teoría jurídica del convenio colectivo..., cit., p. XVIII. 
la idea de que sólo el Estado tenía la capacidad de crear Derecho, desarrollaron un discurso que reconocía fuentes normativas extra estatales, que resultaba apto para cobijar la "configuración del convenio colectivo como categoría jurídica específica" 28 y que partía del reconocimiento en el mismo del "carácter preponderante de la regla jurídica"29.

Dentro de estas corrientes Gallart Folch ${ }^{30}$ identifica, por ejemplo, la encabezada por Otto Friedrich von Gierke, en Alemania; la de los "juristas-sociólogos" italianos, liderados por Enrico Cimbali; el "socialismo jurídico", de Anton Menger, y su célebre obra El Derecho civil y los pobres) y Emmanuel Lévy (La vision socialiste du Droit, 1926); el "sindicalismo doctrinal" de Georges Sorel y Paul-Boncour y otros. A comienzos del siglo XX también se desarrollaron las denominadas corrientes "antiformalistas pluralistas", que plantearon la necesidad de abordar el estudio de las fuentes del Derecho desde una nueva perspectiva y que se expresaron en dos movimientos fundamentales: el de la "lucha contra el fetichismo de la ley", iniciado en Francia por Geny (que profundiza en el análisis del fenómeno jurídico espontáneo) y que es seguido, entre otros, por Cruet, Morin y Lambert; y el del "freirecht" (o Derecho libre), en Alemania, que reconoce a Kantorowicz como su iniciador y que fue seguido por Fuchs y Jung y que tuvo una gran influencia en otros destacados juristas alemanes, como Radbruch, Stammler y Jellinek ${ }^{31}$.

De este modo, sólo cuando pudo dejarse atrás la idea que asignaba a la ley el carácter de fundamento exclusivo de todo el Derecho, se abrió el camino para que pudiera desarrollarse una explicación apta para la naturaleza jurídica del convenio colectivo.

Al respecto Gallart Folch ${ }^{32}$ destaca cuatro corrientes jurídicas fundamentales que se desarrollaron en las tres primeras décadas del siglo XX y que tienen importancia determinante en la explicación de la naturaleza del convenio colectivo. Se trata del "objetivismo solidarista" de Leon Duguit; el "institucionalismo jurídico", de Maurice Hauriou; el "normativismo" de Hans Kelsen y el "espontaneismo jurídico-social", de Ehrlich y Gurvitch. Todas estas corrientes prestaron especial atención al fenómeno del convenio colectivo.

Así, por ejemplo, Duguit, en su célebre conferencia sobre "Las transformaciones generales del Derecho Privado desde el Código Napoleón", dictada en 1911 en Buenos Aires, decía que "El contrato colectivo es una categoría jurídica absolutamente nueva y por completo fuera de los cuadros tradicionales del Derecho Civil. Es una convención-ley que regula las relaciones de dos clases sociales. No es un contrato que produzca obligaciones especiales, concretas y temporales entre dos sujetos de Derecho. Es una ley que establece relaciones permanentes y duraderas entre dos grupos sociales; el régimen legal según el cual deberán pactarse los contratos individuales entre los miembros de estos grupos. He ahí el verdadero punto de vista. He ahí cómo se podrá resolver la dificultad y hacer la teoría jurídica del contrato colectivo"33.

28.- MONEREO PÉREZ, J.L., loc. cit.

29.- GALLART FOLCH, A., Las convenciones colectivas..., cit., p. 112.

30.- GALLART FOLCH, A., Las convenciones colectivas..., cit., p. 91 y ss.

31.- Cfe. GALLART FOLCH, A., Las convenciones colectivas de..., cit., p. 91 y ss. También ver: DE FERRARI, F., Lecciones de Derecho del Trabajo, T. IV, Facultad de Derecho y Ciencias Sociales, Mdeo., 1964., p. 377 y ss. y DE LA CUEVA, M., "El contrato colectivo en la nueva Ley Federal de Trabajo de México", in Estudios en Memoria de Francisco De Ferrari, Facultad de Derecho y Ciencias Sociales, Mdeo., 1973, cit., p. 401 y ss.

32.- GALLART FOLCH, A., Las convenciones colectivas..., cit., p. 100 y ss.

33.- En el caso de GURVITCH, señalaba que el reconocimiento de diversos órdenes jurídicos no era sino la confirmación de la soberanía jurídica de los grupos globales. El convenio colectivo pertenece al grupo de los ordenamientos intermedios de derecho social autónomo, pero con tutela estatal, lo que no supone, sin embargo, su inserción en el sistema de fuentes estatales, sino en el sistema constitucional pluralista de fuentes formales del Derecho (Cfe. MONEREO PÉREZ, J.L., Estudio Preliminar, "Teoría jurídica del convenio colectivo...", cit., p. LVI y ss.). También ver: SINZHEIMER, Hugo, "Teoría de las fuentes del Derecho y el Derecho obrero", in Annuaire de I'Institut International de Philosophie du Droit et de Sociologie juridique (1934-1935), Travaux de la première session. Le problème de sources du Droit Positif, Paris, 1934, traducido por la Dra. María Inés Capucho. 
Por su parte, Hauriou, al concebir la noción de la institución, reconocía que ciertos "poderes organizados", que no necesariamente pertenecen al Estado, pueden tener la capacidad de crear Derecho ${ }^{34}$. A partir de estas ideas de Hauriou, otros autores franceses institucionalistas, como Cuche y Gounot ${ }^{35}$, hablaron del convenio colectivo como una "institución-regla" o se refirieron al instrumento como el estatuto de una institución cuya base social es la agrupación productora.

Hans Kelsen opinaba que el convenio colectivo debía ser ubicado en un grado intermedio entre acto individualizado y ley (acto normativo), "no sólo porque estatuyen normas generales bajo la forma convencional, sino también porque el principio de la autonomía típico para el acto jurídico, es en ellos francamente relegado a un segundo plano por el principio de la heteronomía, característico de la ley" (la expresión autonomía se toma en sentido que sólo alcanza a los pactantes y heteronomía, como creación de reglas que alcanzan a terceros). El maestro vienés agregaba, además que entre el convenio colectivo y la ley "la diferencia es mínima. La convención colectiva aseméjase profundamente a la ley. Ello significa que lo que predomina en esta clase de convenios no es el principio de autonomía, sino el principio de la heteronomía, específico de la ley"36.

Algunas teorías pretendieron explicar la naturaleza normativa del convenio colectivo señalando que la misma deriva de un reconocimiento estatal (teoría de la ley delegada, teoría del reglamento administrativo, etc.). Al respecto, Gallart Folch sostenía que era un error “...creer que el Estado o la administración pública confieran a los organismos sindicales, patronales y obreros, el poder normativo en virtud del cual éstos pueden regular, por mutuo acuerdo, las condiciones de trabajo dentro de una profesión u oficio". Para advertir dicho error, dice el autor, "No hay más que recordar el proceso evolutivo de las convenciones colectivas..." y al respecto sostenía que "...puede sentarse, sin temor a rectificación, la tesis siguiente: no es que los sindicatos patronales y obreros empezaran a regular las condiciones de trabajo en la profesión u oficio el día que recibieron ese encargo o delegación del Estado, sino que el Estado reconoció el valor jurídico normativo en las convenciones intersindicales cuando esta actividad era ya una realidad indiscutible" 37 .

El propio Gallart cita a Georges Scelle, cuando éste expresa: "Si analizamos con criterio realista las cosas constataremos que cada rama de la industria, cada fábrica, cada taller, se presenta como una especie de pequeña comunidad y persigue un fin social: una producción determinada. Cada uno de estos cosmos, pequeño o grande, tiene su organización propia, sus autoridades, su jerarquía, sus leyes, sus sanciones. En él tuvimos mucho tiempo una autoridad única: el patrono. Esa forma monárquica de la institución tiende a desaparecer por la participación de los gobernados en el poder. El grupo profesional participa en el régimen social de la empresa y todo eso se concreta en un instrumento convencional que apodan contrato colectivo, pero que es toda otra cosa que el contrato colectivo, pues es el conjunto de reglas que presiden a la producción, en una fábrica, en una industria, a veces en toda una rama de actividad del país" ${ }^{38}$.

\section{Consideraciones finales: La negociación colectiva como valor objeto de tutela y ubicación del convenio colectivo en el sistema de las fuentes}

Los ordenamientos jurídicos han jerarquizado hoy la protección de la negociación colectiva, así como la posibilidad de desarrollarla en forma libre y plena, definiéndola como un valor o bien jurídico que ha alcanzado a constituirse en objeto de tutela jurídica privilegiada.

34.- HAURIOU, Maurice, La teoría de la institución y de la fundación. Ensayo de vitalismo social, Abeledo-Perrot, Bs. As., 1968, p. 48. V. GALLART FOLCH, A., op. cit., p. 100 y ss.

35.- Respectivamente: Manifestations nouvelles d'autorité dans la vie sociale par le developpement de l'Institution. Compte rendu de la Semaine Social de Lyon, París, 1925 y L'autonomie de la volonté. Contribution a l'etude critique de l'individualisme juridique, París, 1912. Ambos citados por GALLART FOLCH, A., op. cit., p. 102.

36.- KELSEN, Hans, Las transformaciones del Derecho, Heliasta, Bs. As., 1975, p. 81 y ss., cit. por MONEREO PÉREZ, J.L., Estudio Preliminar "Teoría jurídica del convenio colectivo ..., op. cit., p. LI. (EI contrato y el tratado analizados desde la teoría pura del Derecho, México, Ed. Nacional, 1943 (reimp. 1974), p. 145 y ss., cit. por MONEREO PÉREZ, J. L., Estudio Preliminar, cit. p. LII y ss.

37.- GALLART FOLCH, A., op. cit., p. 121.

38.- SCELLE, Georges, "La loi de huit heures", en Revue politique et parlamentaire, 1920, p. 27, cit. por GALLART FOLCH, A., op. cit., p. 121 
Por una parte, está indisolublemente asociada a la libertad sindical, que es su antecedente indispensable y a la que, a su vez, está en condiciones de retribuir como elemento potenciador de su efectiva vigencia y profundización. Así es reconocido en el Convenio Internacional de Trabajo 98, sobre derecho de sindicación y de negociación colectiva ${ }^{39}$; de tal suerte que sólo es posible concebir una negociación colectiva auténtica donde previamente esté asegurado el pleno reconocimiento de la libertad sindical.

Por otra parte, el reconocimiento y amparo del derecho de huelga representa la consagración de un respaldo elemental para la existencia de la negociación colectiva, al constituirse a su respecto, en un factor de coercibilidad, que posibilita, no solamente que esta última pueda comenzar en cuanto proceso, sino también, que pueda culminar como tal, eventualmente a través de la celebración de un convenio colectivo ${ }^{40}$.

Tal es la importancia que la conciencia jurídica global les reconoce a estos valores, que la Declaración sobre Principios y Derechos Fundamentales en el trabajo y su seguimiento (adoptada en 1998 por la 86 ${ }^{\text {a }}$ Conferencia General de la OIT), incluye "a la libertad de asociación y a la libertad sindical y al reconocimiento efectivo del derecho de negociación colectiva" dentro de la nómina de principios y derechos fundamentales ${ }^{41}$ que los Estados Miembros de la Organización (por el mero hecho de serlo y con independencia de que hayan o no ratificado los instrumentos que específicamente los consagran); se obligan a respetar, promover y hacer realidad de buena fe.

Esto significa que la negociación colectiva (que a estos efectos, naturalmente, debe considerarse comprensiva de la posibilidad de culminarla mediante la celebración de un convenio colectivo) es concebida en la actualidad formando parte de un esquema de valores superiores, inherentes a la condición humana, cuya trascendencia determina que su vigencia y eficacia plena no pueda depender del efectivo ejercicio por parte de los Estados de un acto de soberanía (como lo es la ratificación de los convenios internacionales de trabajo que los consagran), sino que en todo caso deben ser objeto de aplicación inmediata y automática ${ }^{42}$.

Es así que los mismos institutos que, según se indicó más arriba, fueron penalizados en el pasado, en la actualidad han mutado notablemente su situación, al punto de pasar a ser considerados bienes jurídicos fundamentales, identificados como elementos esenciales para la conformación de una estructura social sana y plural, condición básica para el sustento de una democracia verdadera ${ }^{43}$ y cuyo amparo ha alcanzado el rango de derecho humano

39.- Art. 4: "Deberán adoptarse medidas adecuadas a las condiciones nacionales, cuando ello sea necesario, para estimular y fomentar entre los empleadores y las organizaciones de empleadores, por una parte, y las organizaciones de trabajadores, por otra, el pleno desarrollo y uso de procedimientos de negociación voluntaria con objeto de reglamentar, por medio de contratos colectivos, las condiciones de empleo"

40.- La relación existente entre la negociación y la huelga es ilustrada muy gráficamente por Ulrich ZACHERT, quien a tales efectos recurre a un pronunciamiento del Tribunal Federal del Trabajo alemán: "Negociaciones colectivas sin derecho de huelga en general no serían otra cosa que un mendigar colectivo". ZACHERT, Ulrich, "Autonomía de los sindicatos e intervención en la negociación colectiva", in La negociación colectiva en América Latina (Antonio OJEDA AVILÉS y Oscar ERMIDA URIARTE, Editores), Trotta, Madrid, 1993, p. 137.

41.- Dicha nómina se completa con la eliminación del trabajo forzoso, la abolición efectiva del trabajo infantil y la eliminación de la discriminación en el empleo y la ocupación.

42.- Estas referencias adquieren especial importancia a la luz de lo establecido en el artículo 1ㅇde la ley № 18.508, del 26 de junio de 2009 (sobre negociación colectiva en el sector público) y, asimismo, en el artículo 10 de la ley № 18.566, del 11 de setiembre de 2009 (sobre negociación colectiva en el sector privado), que disponen que el sistema de ambas leyes también se inspira en los derechos fundamentales internacionalmente reconocidos.

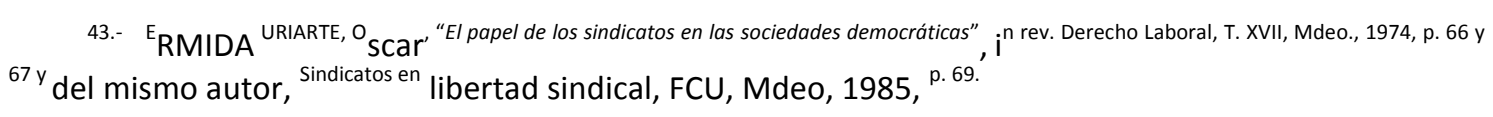


fundamental ${ }^{44}$. En este estado, vuelven a aparecer en diversos ordenamientos del Derecho comparado, tipos penales referidos a las cuestiones laborales colectivas, aunque, naturalmente, asumiendo ahora un rol exactamente inverso al que desplegaban poco más de un siglo atrás, al sancionar las conductas que desconocen o pretendan obstaculizar el pleno desarrollo y vigencia de los mismos, ahora considerados merecedores de tutela jurídica superlativa ${ }^{45}$. De este modo, se les ubica como "...un núcleo esencial de derechos e intereses que el ordenamiento laboral debe intentar preservar, también mediante el instrumento que le suministra al Estado la tutela pena ${ }^{46}$.

En cuanto al convenio colectivo, si bien todavía no ha dejado de ser un tema controversial y continúa planteando "...un problema para la teoría general de las fuentes en Derecho, con independencia de la recepción concreta o específica de las instituciones colectivas en el ordenamiento estatal ${ }^{47}$, parece estar bastante asentada su conceptualización como una norma jurídica que reconoce origen y fundamento autónomo del poder normativo del Estado.

44.- Declaración Universal de los Derechos Humanos (artículo 23), Pacto Internacional de los Derechos Civiles y Políticos (artículo 22), Pacto Internacional de los Derechos Económicos, Sociales y Culturales (artículo 8), Convención Americana de Derechos Humanos (artículo 15), Convención Europea de Salvaguarda de los Derechos del Hombre (artículo 11), Carta Social Europea, Declaración de la OIT relativa a principios y derechos fundamentales en el trabajo y su seguimiento (86ạ sesión de la Conf. General, junio de 1998); Declaración Sociolaboral del Mercosur (arts. 8 a 13), Proyecto de Constitución europea (por ej.: Parte II,

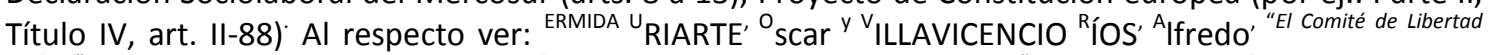
Sindical", en rev. Derecho Laboral' T. XXXVI, Mdeo.,1993, p. 79-80, 'PLÁ RODRÍGUEZ' A., "Convenios internacionales sobre libertad sindical"' in rev. Derecho Laboral, t. XIII, Mdeo., 1962, p.185, I BÁÑEZ' M anuel' "La libertad sindical y los derechos humanos »"

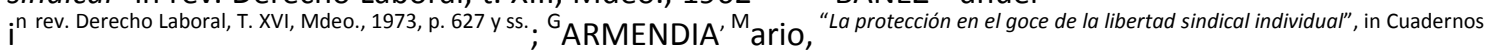
de la Facultad de Derecho, segunda serie, № 21, 7 Estudios de Derecho Colectivo del Trabajo, FCU, 1994.

, VV.AA., Eficacia jurídica de la Declaración Sociolaboral del Mercosur, Asociación Argentina de Derecho del Trabajo - Oficina Internacional del Trabajo, Bs. As., 2002.

45.- En España, el Código Penal de 1995 (Ley Orgánica 10/995) dedica el Título XV (artículos 311 a 318) a los delitos "contra los derechos de los trabajadores" y dentro de éstos incluye la protección penal del principio de autonomía colectiva y de las reglas de actuación colectiva. Cfe. BAYLOS, A. Y TERRADILLOS, J., op. cit., p. 31 y NARVAEZ BERMEJO, Miguel A., Delitos contra los derechos de los trabajadores y la Seguridad Social, Tirant lo Blanch, Colección Laboral, 60, Valencia, 1997, p. 13. En Italia también son tipificados diversos ilícitos penales, tanto en el Código Penal como en el Statuto dei Lavoratori, entre los cuales resalta el delito consagrado en el art. 28, ord. 4 del Statuto, que se remite al art. 650 del C. Penal y sanciona al empleador que no acata la orden judicial de cesar su comportamiento antisindical y remover sus efectos (PERA, Giuseppe, Diritto del Lavoro, 5a ed., Cedam, Milán, 1995, p. 607 y ss.; GHEZZI, Giorgio, ROMAGNOLI, Umberto, II diritto sindacale, 2a ed., Zanichelli, Bologna, 1987, p. 290). En Francia, se tipifica el délit d'entrave (delito de traba u obstaculización, L. 482-1), que se configura ante cualquier acción u omisión en que incurra el empleador que provoque trabas en la libre designación o ejercicio del mandato de los representantes de los trabajadores. La sanción consiste en una pena de prisión (de dos meses a un año) o multa pecuniaria (Cfe. JAVILLIER, Jean Claude, Manuel de Droit du Travail, 2a ed. Paris, 1988, p. 327 y 328). En América Latina, puede mencionarse por ejemplo el caso Brasil, donde el Código Penal incluye un capítulo titulado "Dos crimes contra a organização do trabalho" (artículos 197 a 207) que contempla tipos penales que, en algunos casos parecen tener por finalidad la protección de la actividad económica o de la denominada "libertad sindical negativa" (por ejemplo: "atentado contra la libertad de trabajo" -art. 197, "atentado contra la libertad de contrato de trabajo y boicot violento" -art. 198, "paralización del trabajo, seguida de violencia o perturbación del orden" -art. 200, "paralización de trabajo de interés colectivo" -art. 201, "invasión de establecimiento industrial, comercial o agrícola. Sabotaje" -art. 202) y en otros parece buscarse la tutela de la libertad sindical (por ejemplo: "atentado contra la libertad de asociación", del art. 199) Cfe. MASCARO NASCIMENTO, Amauri, Iniciação ao Direito do Trabalho, 28a ed., LTR, São Paulo, 2002, 648. En el caso de Argentina, se ha indicado que si bien el Código Penal contempla diversas formas de punición en tanto se atente contra la vida, la integridad física, la honra, la libertad, etc., de los trabajadores; en cambio no se han adoptado en ningún caso tipos o figuras especiales que contemplen específicamente su condición de tales (Cfe. ARESE, César, Derecho Penal del Trabajo y la Seguridad Social, Unidad Primera, Universidad Nacional de Córdoba, Facultad de Derecho y Ciencias Sociales, CD-rom).

46.- BAYLOS, A. y TERRADILLOS, J., op. cit., p. 34.

47.- MONEREO PÉREZ, J.L., Teoría jurídica del convenio colectivo..., cit., p. XXXVIII. 
Con preclara visión, en las primeras décadas del siglo pasado, Gallart Folch hacía hincapié en esa característica autonomía del convenio colectivo, que es resultado de su propio origen histórico. "Las convenciones colectivas de normas de trabajo -decía el autor- no nacieron por iniciativa del Estado y de la administración pública, sino como resultado de una actividad sindical al principio perseguida y luego sólo tolerada por el Estado. Esta regulación de condiciones de trabajo, tan precariamente nacida, fue ignorada durante mucho tiempo por la ley. Cuando la importancia de este fenómeno normativo espontáneo reclamó ineludiblemente la atención los hombres de gobierno, las legislaciones empiezan a ocuparse de él, en general, en forma muy incompleta, y sólo algunas planteándolo y tratándolo de resolver en toda su amplitud. Por eso puede sentarse, sin temor a rectificación, la tesis siguiente: no es que los sindicatos patronales y obreros empezaran a regular las condiciones de trabajo en la profesión u oficio el día que recibieron ese encargo o delegación del Estado, sino que el Estado reconoció el valor jurídico-normativo de las convenciones intersindicales cuando esta actividad era ya una realidad indiscutible"48.

$\mathrm{Y}$, precisamente, atendiendo a este particular nacimiento, es que el mismo autor señalaba el error de "...tratar de estudiar y, consecuentemente, de explicar el fenómeno jurídico social de arriba abajo, cuando el estudio debió hacerse y la explicación debió intentarse de abajo a arriba" $"$.

El ordenamiento laboral se consolidó, así, como un sistema complejo de normas que reconocen fuentes diversas, algunas heterónomas, es decir, originadas en la autoridad estatal y otras autónomas o extra estatales, que parten de la premisa de la existencia de una potestad normativa que tiene origen en el cosmos de cada unidad productiva, que en sus orígenes fue acaparada por el patrono y que luego adoptó la forma de un instrumento convencional que se consagra las reglas que rigen el desenvolvimiento del trabajo ${ }^{50}$.

En buena medida, el Derecho del Trabajo y, en particular, el convenio colectivo, tomaron la forma de ariete que arremetió contra las doctrinas que sólo reconocían al Estado la capacidad de producir normas jurídicas y contribuyeron a abrir una brecha que hoy ha adquirido dimensiones bastante más amplias, para abarcar prácticamente a la totalidad del universo del Derecho, tal como señala Ferrajoli ${ }^{51}$.

El reconocimiento de la autonomía del convenio colectivo no significa, empero, que sea correcto sostener que posea una existencia autárquica respecto del sistema normativo estatal. En realidad, ambos sistemas pueden asumirse como integrados en un sistema constitucional unitario, erigido, no ya a partir de elementos de tenor meramente formal, sino sobre la base de "...un conjunto de principios y valores constitucionales superiores, sobre los que, a pesar de todo, existe un consenso social suficientemente amplio"52.

El orden para aquel complejo sistema jurídico laboral quedó pautando sobre la base de que las normas estatales habrían de conformar una red protectora y de garantías mínimas,

48.- GALLART FOLCH, A., op. cit., p. 121.

49.- GALLART FOLCH, A., op. cit., p. 120.

50.- GALLART FOLCH explicaba el origen de esa "regulación bilateral espontánea" citando a Georges SCELLE, cuando éste señalaba que "...cada rama de la industria, cada fábrica, cada taller, se presenta como una especie de pequeña comunidad y persigue un fin social: una producción determinada. Cada uno de estos cosmos, pequeño o grande, tiene su organización propia, sus autoridades, su jerarquía, sus leyes, sus sanciones. En él tuvimos mucho tiempo una autoridad única: el patrono. Esta forma monárquica de la institución tiende a desaparecer por la participación de los gobernados en el poder. El grupo profesional participa en el régimen social de la empresa, y todo eso se concreta en un instrumento convencional que apodan contrato colectivo, pero que es toda otra cosa que el contrato colectivo, pues es el conjunto de reglas que presiden a la producción, en una fábrica, en una industria, a veces en toda una rama de actividad del país" (SCELLE, G., "La loi de huit heurs", in Revue politique et parlamentaire, 1920, cit. por GALLART FOLCH, A., op. cit., p. 121).

51.- FERRAJOLI, Luigi, Derechos y garantías. La ley del más débil, Trotta, 4a ed., Madrid, 2004, p. 28 y ss.

52.- ZAGREBELSKY, Gustavo, El derecho dúctil, Trotta, Madrid, 1995, p. 40 y ss. 
indisponibles a la baja, en tanto que las normas convencionales tradicionalmente tuvieron adjudicado el rol de asumir la forma de instrumentos de progreso continuo de los beneficios de los trabajadores, mediante la superación negociada de los niveles mínimos establecidos por las normas heterónomas. Sin embargo, la historia y las coyunturas se han encargado de ir mutando los roles normativos asumidos por unos y otros, dando la razón a la aguda puntualización de Monereo, cuando señala que "La figura del convenio colectivo no tiene naturaleza inmanente, porque nada en él es invariable. En vez de naturaleza tiene Historia" ${ }^{53}$.

\section{REFERÊNCIAS}

BARBAGELATA, H.-H., Curso sobre la Evolución, cit., p. 134 y MONEREO PÉREZ, J.L., cit., p. XVIII y XXIX.

BARBAGELATA, Héctor-Hugo, Curso sobre la Evolución del Pensamiento Juslaboralista, FCU, Mdeo., 2009, p. 16 y ss.

BAYLOS Grau, Antonio, y TERRADILLOS, Juan, Derecho Penal del Trabajo, Trotta, Madrid, 1990, p. 15.

BERTOZZO, Matthieu, “Le décret d'Allarde des 2 et 17 mars 1791 ou la matérialisation des idées libérales de la Révolution française", Revue Générale du Droit, http://www.revuegeneraledudroit.eu

BRUN, André y GALLAND, Henri, Droit du Travail, 2ª ed., t. I, Sirey, París, 1978, p. 8.

CAMERLYNCK, G.H. y LYON-CAEN, G., Derecho del Trabajo, trad. de la 5a ed. francesa, Ed. Aguilar, Madrid, p.1.

CARNELUTTI, Francesco, Lezioni di diritto industriale: teoria del regolamento collettivo dei rapporti di lavoro, A. Milani, 1927, p. 108.

DE FERRARI, F., Lecciones de Derecho del Trabajo, T. IV, Facultad de Derecho y Ciencias Sociales, Mdeo., 1964., p. 377 y ss

DE LA CUEVA, Mario. El Nuevo Derecho Mexicano del Trabajo, t. I, Porrúa, 19ª edición, México, 2003, p. 17.

DE LA CUEVA, Mario, "El contrato colectivo en la nueva Ley Federal de Trabajo de México", in Estudios en Memoria de Francisco De Ferrari, Facultad de Derecho y Ciencias Sociales, Mdeo., 1973, p. 401.

DURAND, Paul y JAUSSAUD, R., Traité de Droit du Travail, T. I, Dalloz, París, 1947, p. 62;

ERMIDA URIARTE, Oscar y VILLAVICENCIO RÍOS, Alfredo, “El Comité de Libertad Sindical”, en rev. Derecho Laboral, T. XXXVI, Mdeo.,1993, p. 79-80; 
ERMIDA URIARTE, Oscar, "El papel de los sindicatos en las sociedades democráticas", in rev. Derecho Laboral, T. XVII, Mdeo., 1974, p. 66 y 67

ERMIDA URIARTE, Oscar. Sindicatos en libertad sindical, FCU, Mdeo, 1985, p. 69.

Ferrajoli, Luigi, Derechos y garantías. La ley del más débil, Trotta, 4ae ed., Madrid, 2004, p. 28 y ss.

Gallart Folch, Alejandro, Las convenciones colectivas de trabajo en la doctrina y en las legislaciones extranjeras y española, Comares, Granada, 2000, p. 14, con importante prólogo de José Luis MONEREO PÉREZ.

GALLINAL, Gustavo, "Últimas transformaciones de la legislación del trabajo en Francia", in Ensayos, № 15, Mdeo., setiembre de 1937, p. 12.

GARMENDIA, Mario, "La protección en el goce de la libertad sindical individual", in Cuadernos de la Facultad de Derecho, segunda serie, № 21, 7 Estudios de Derecho Colectivo del Trabajo, FCU, 1994; VV.AA., Eficacia jurídica de la Declaración Sociolaboral del Mercosur, Asociación Argentina de Derecho del Trabajo - Oficina Internacional del Trabajo, Bs. As., 2002.

GARMENDIA, Mario. "La empresa y sus mutaciones desde la perspectiva del Derecho del Trabajo", in rev. Derecho Laboral, № 229, enero-marzo 2008.

HAURIOU, Maurice, La teoría de la institución y de la fundación. Ensayo de vitalismo social, Abeledo-Perrot, Bs. As., 1968, p. 48

IBÁÑEZ, Manuel, "La libertad sindical y los derechos humanos", in rev. Derecho Laboral, T. XVI, Mdeo., 1973, p. 627 y ss.;

JAVILLIER, Jean Claude, Manuel de Droit du Travail, $2^{\mathrm{a}}$ ed. Paris, 1988, p. 327 y 328 ).

KELSEN, Hans, Las transformaciones del Derecho, Heliasta, Bs. As., 1975, p. 81 y ss.,

LOTMAR, Phillip, "Contratti di tariffa tra datori e prestatori di lavoro", in Giornale di diritto del lavoro e di relazioni industriali (DLRI), ㄲo 22, 1984, p. 309 y ss.

MASCARO NASCIMENTO, Amauri, Iniciação ao Direito do Trabalho, 28aㅡ ed., LTR, São Paulo, 2002, 648.

MONEREO PÉREZ, José Luis, Teoría jurídica del convenio colectivo: su elaboración en la ciencia de Derecho. Estudio Preliminar al libro de GALLART FOLCH, Las convenciones colectivas de condiciones de trabajo en la doctrina y en las legislaciones extranjeras y española, Comares, Granada, 2000, p. XI.

NARVAEZ BERMEJO, Miguel A., Delitos contra los derechos de los trabajadores y la Seguridad Social, Tirant lo Blanch, Colección Laboral, 60, Valencia, 1997, p. 13.

OLSZAK, Norbert, Histoire du Droit du Travail, ed. Economica, Paris, 2011, p. 23-24.

PALACIOS, Alfredo L., El Nuevo Derecho, Lajouane \& Cía., Editores, Bs. As., 1920, p. 170 y 174

PERA, Giuseppe, Diritto del Lavoro, 5aㅡ ed., Cedam, Milán, 1995, p. 607 y ss.; GHEZZI, Giorgio, ROMAGNOLI, Umberto, II diritto sindacale, 2ª ed., Zanichelli, Bologna, 1987, p. 290

PIROU, Gaëtan, "Les problemes de contrats collectifs de travail en France", Revue Intern. du Travail, Vol. V, 1922, p. 41, cit. por GALLART FOLCH, A., op. cit., p. 13.

PLÁ RODRÍGUEZ, A., "Convenios internacionales sobre libertad sindical", in rev. Derecho Laboral, t. XIII, Mdeo., 1962, p.185.

SCELLE, Georges, "La loi de huit heures", en Revue politique et parlamentaire, 1920, p. 27, cit. por Gallart Folch, A., op. cit., p. 121 
SIMITIS, Spiros, "La legge Le Chapelier tra storia e attualità", in rev. Diritto del Lavoro e Relazioni Industriali, $N^{\circ} 48,1990$.

SINZHEIMER, Hugo, "Teoría de las fuentes del Derecho y el Derecho obrero", in Annuaire de I'Institut International de Philosophie du Droit et de Sociologie juridique (1934-1935), Travaux de la première session. Le problème de sources du Droit Positif, Paris, 1934, traducido por la Dra. María Inés Capucho.

SINZHEIMER, Hugo, "La théorie des sources du droit et le droit ouvrier", in Annuaire de l'Institut International de Philosophie du Droit et de Sociologie Juridique, 1934-1935, pp. 72-81.

ZACHERT, Ulrich, "Autonomía de los sindicatos e intervención en la negociación colectiva", in La negociación colectiva en América Latina (Antonio OJEDA AVILÉS y Oscar ERMIDA URIARTE, Editores), Trotta, Madrid, 1993, p. 137.

ZAGREBELSKY, Gustavo, El derecho dúctil, Trotta, Madrid, 1995, p. 40 y ss. 